\title{
Notes on the Influence of DESIGN ON EXPRESS LOCOMOTIVE Performance.
}

Paper read before the Institution by CECIL J. ALLEN, Associate, London, 6th January in Manchester, 26th January in London, and ${ }^{1} 3^{\text {th }}$ March, 1922, in Leeds.

\section{PAPER No. 117.}

An examination of the Proceedings of this Institution during past years reveals the fact that papers read before its members dealing directly with the subject of locomotive performance on the road are, generally speaking, in the minority. It is only natural that in an Institution composed mainly of those concerned in the construction of locomotives, technical questions concerning the design, the construction and the operating of the engine, viewed chiefly from the maintenance standpoint, should take the premier place in the discussions. The ultimate aim of these discussions is doubtless that the locomotive of the present and of the future shall, by such interchange of thought and idee, become as economical in manufacture, running and maintenance as it is possible to make it; that is to say, the object in view is the attainment of maximum efficiency, so far as maintenance is concerned. Broadly speaking, this might be described as the duty of a locomotive department to the proprietors of the railway. But at the same time there must be considered the duty of the same department 
to the public, in which again the locomotives are intimately concerned. The latter duty is expressed in the published time-tables, for the fulfilment of whose promises the locomotive department is called upon to design, construct and supply the necessary power. When so viewed, performance becomes a matter of no less importance than design, and yet the amount of scientific data available in regard to the former-at any rate, the published data-is negligible in comparison with the mass of information relative to the latter. There would seem at times a tendency to regard the locomotive that has proved its capability of hauling a train of average loading. from $A$ to $B$ at the speed laid down by the operating department of the railway concerned without thrashing and on a reasonable consumption of fuel, as performing its duties to such satisfaction that no further research into its performance is required. To the Author this appears an inadequate treatment of an important question.

In opening up the subject of this evening's Paper, the Author desires to suggest lines along which the influence of design upon performance may be considered, rather than attempt to lay down any definite relation between dimensions and work done. Accurately to define that relation, indeed, is difficult, if not impossible, owing to the number and complexity of the factors involved. In designing a locomotive, for which we may assume that certain demands. in regard to tractive power have been made by the operating department of the railway, we have recourse, first, to the ordinary tractive force formula. This is based upon cylinder diameter, stroke, working steam pressure and the diameter of driving wheels. But it takes no account of the capacity of the boiler to raise steam, nor of the proportion of the engine weight available for adhesion ; and inadequacy of steam supply or inadequacy of adhesion may falsify the results of any calculation obtained from the tractive force formula alone. We therefore have recourse to ratios; tractive effort to heating surface, tractive effort to adhesion, heating surface to grate area, and so on, in order to seek to lay down some dimensional basis for arriving at the work to be performed by the engine. But here again it is impossible to guarantee accuracy of result. Heating surface may total a high figure, but the boiler may be so crowded with small tubes as to steam badly; the fire-grate may be large, as regards area, but so long and narrow as to prove difficult to fire, and so afford results incommensurate with its size; adhesion may appear ample, so far as tonnage is concerned, but the absence of steam sanding, 
say, on a route subject to driving mists and a greasy rail, may upset all results arrived at on an adhesion-tonnage basis. Further, if proof were needed that thic relation between such dimensional ratios and locomotive performance is at present ill-defined, it can be found in the marked variation in ratios adopted by one locomotive engineer as compared with another.

Perhaps the most striking comparison that could be made would be between the $8 \mathrm{ft}$. single-driver engines of Mr. Patrick Stirling's design, and the Ivatt " Atlantics "the standard express locomotive designs of two succeeding locomotive superintendents of the same railway. The former locomotives incorporated cylinders I $8 \mathrm{in}$. in diameter by $28 \mathrm{in}$. stroke, and supplied them with steam from a boiler affording $1,032 \mathrm{sq}$. $\mathrm{ft}$. of heating surface, and pressed to 1 olb. per sq. in.; the ratio of tractive effort, at 80 per cent. working pressure, to heating surface was therefore one of 10. I 5 lb. to I sq. ft. Ivatt's 6ft. $7 \frac{1}{2} \mathrm{in}$. "Atlantics," prior to superheating, had $18 \frac{3}{4}$ in. by $24 \mathrm{in}$. cylinders, with a $5 \mathrm{ft}$. $6 \mathrm{in}$. boiler pressed to $\mathrm{I} 75 \mathrm{lb}$. per sq. in., and containing $2,500 \mathrm{sq}$. $\mathrm{ft}$. of heating surface; the corresponding ratio in this case was therefore $5.941 \mathrm{lb}$. to $\mathrm{I}$ sq. $\mathrm{ft}$. In proportion to their weight, both types of engine may be claimed to have performed work of approximately equal merit over the sime road, and yet the difference in this essential ratio was as IO. I 5 to 5.94 . In his final batch of $8 \mathrm{ft}$. singles Stirling presumed on the success of the earlier engines to increase his cylinder diameter to as much as $19 \frac{1}{2}$ in., with the intention of enhancing his tractive capacity without any corresponding increase in the steam-producing capacity of the boiler. Thus the ratio in question rose to as much as II.9Ilb. per sq. ft. or exactly twice the ratio of the Ivatt "Atlantics," but in this final development Stirling appears somewhat to have overstepped what was practical, and the engines were not so successful in performance as their predecessors, being undoubtedly over-cylindered. Similar contrasts could be found in numbers in present-day practice. To mention an extreme case, the superheated 2-4-2 tank engines of the Lancashire and Yorkshire Railway, frequently emploved on express duties, with 20 by 26in. cylinders and only $920 \mathrm{sq}$. ft. of heating surface, afford a remarkable comparison with the superheated Great Northern " Atlantics," with their 20 by 24 in. cylinders and $2,396 \mathrm{sq}$. $\mathrm{ft}$. of heating surface-a ratio of $24^{\mathrm{lb}}$. tractive effort per sq. ft. of heating surface in the former case, as against 6.5 in the latter. Similar results would be obtained by a comparison of the ratios between other leading dimen- 
sions ; such results, which might be quoted in numbers, go to prove, not only that we are as yet far from any fixed standards in the relation of one set of locomotive dimensions to another (even in the case of engines called upon to perform approximately the same work), but also that, if engines of varied proportions are capable of making the same times with the same loads over the same road, it is impossible to arrive at an accurate estimate of locomotive performance from a consideration of dimensions alone.

Similar considerations apply in the matter of dimensions which may be regarded as minor dimensions, and yet have a vital influence on the working of the engine. For example, a variation of one-quarter of an inch in the diameter of a blast orifice may make all the difference in the behaviour of that engine under continuous steam. And yet it would be beyond the power of the most mathematically-minded of locomotive engineers to devise a formula which would take into account size of cylinders, diameter of wheels, working steam pressure, heating surface, superheating surface, area of fire-grate, diameter of blast orifice, and so on, and from it deduce that the engine in question, with a load, say, of $3 \mathbf{I} 2$ tons on a rising gradient of $\mathrm{I}$ in 405 , would maintain a speed of precisely 5.7 miles per hour.

Further, locomotive engineering practice differs from the practice of nearly all other types of steam engine in that it has no recognised standard of efficiency, i.e., efficiency of actual performance in relation to the calorific value of the fuel burned, through the medium of those leading dimensions whereby the energy of the fuel is translated into useful work. Comparison of the results achieved by locomotives running under different conditions of load, speed and weather to arrive at an estimate of this efficiency, involve one in calculations of such appalling complexity as to be well-nigh out of the question, and isolated experimental tests cannot be more than approximately true of average working conditions.

The relation between design and performance is still further complicated by other considerations not yet considered. It is a well-known fact that no two locomotives, of precisely the same design and dimensions, are absolutely the same in their performance on the road, even though in the hands of the same crew. Minute variations in the accuracy of erection, and other details connected with the manufacture of the different engines of a single batch are sufficient in their effect on the performance to give one engine a good name and another a bad one, among those responsible for working them. Herein is doubtless the 
principal predisposing cause of those human characteristics with which the locomotive has been credited from time to time. Add to this the variation in driving method, as between one driver and another, and all results arrived at by calculation are rendered of still less value. To quote from an article in the "Railway Engineer," for which the Author was responsible, one driver will " nurse" his engine on uphill grades, and run freely at high speeds downhill; another may " extend" his engine uphill-in an endeavour to adhere to those sanguine sectional times so beloved of the compilers of working time-books, who frequently demand the impossible uphill, while refusing to recognise the average speeds invariably and safely run downhill - and may shut off steam on the falling gradients; a third, having regard to the coal bonus, may adopt the "ca' canny" policy throughout the journey, while perhaps trying to make up the time he has lost thus by running too fast over sections of severely restricted speed; and a fourth, after the fashion rendered immemorial by Jehu, may "drive furiously" from start to finish. It will be argued that such variations in driving have no real bearing on the relation between design and performance, but at least they help to make that relation, if based on average daily performance, the more difficult accurately to define.

In order that at least one branch of this ramified subject may be considered this evening in closer detail, the Author proposes now to discuss briefly the considerations as. regards design bearing upon the maximum speed capacity of express locomotives. Theoretically, the maximum speed of which an engine is capable should vary in proportion to the diameter of its driving wheels, seeing that the diameter varies inversely as the speed of the moving parts as a whole. Piston speed varies directly with the length of the stroke, and an increase in piston stroke should therefore adversely affect speed capabilities. Again, the added internal resistance of a locomotive occasioned by coupling two axles rather than using a single driving wheel, or by coupling three axles instead of two, should progressively reduce the capacity of an engine for high speed.

Within broad limits, these conclusions have been verified by certain well-known experiments in the past: The late Mr. Dugald Drummond read a paper before the Institution of Mechanical Engineers in 1904, giving the results of trials conducted by him on the London and South Western Railway between two 4-4-o express engines having driving wheels of the nominal diameters of $6 \mathrm{ft}$. 7 in. and $7 \mathrm{ft}$. Iin. respectively. Wear of the tyres had reduced those 
diameters to $6 \mathrm{ft}$. $5 \frac{3}{8} \mathrm{in}$. and $6 \mathrm{ft}$. $10_{4}^{3} \mathrm{in}$. at the time of the tests; piston stroke in both cases was $26 \mathrm{in}$. The experiments consisted in running the two engines with their tenders light at high speeds over a short stretch of level track, careful records being taken of the positions of regulator and reversing gear, while at the same time the engines were indicated. As a result it was proved that, up to a speed of $62 \mathrm{~m} . \mathrm{p} . \mathrm{h}$., the smaller-wheeled engine required less horse-power to propel itself than the one with the larger wheels; at $42 \mathrm{~m}$.p.h. the difference was as great as $170 \mathrm{~h} . \mathrm{p}$., the figures being about 150 for the former against 320 for the latter. But at $70 \mathrm{~m} . \mathrm{p} . \mathrm{h}$. the position was reversed, the $7 \mathrm{ft}$. Iin. engine needing 700 horse-power for its own propulsion as against the 9 ro horse-power of the $6 \mathrm{ft}$. 7 in. engine. Thus the relation between driving wheel diameter and maximum attainable speed was clearly proved, despite the fact that the larger-wheeled engine was both older and in less good repair than the smaller, in addition to suffering the disadvantage, on account of outside cylinders, of a $13^{\text {in. }}$. coupling rod throw as compared with gin. in the case of its rival.

Again, we have the famous experiment made by Mr. H. A. Ivatt between a single-driver express engine and an eight-coupled mineral engine, both of his own design, the former having $7 \mathrm{ft}$. 7 in. driving wheels and the latter $4 \mathrm{ft}$. $8 \mathrm{in}$. As a result of these trials it was proved that the eight-coupled engine exerted a drawbar pull of ro tons on starting, as against the 5 tons of the single, and at speeds up to $20 \mathrm{~m} . \mathrm{p} . \mathrm{h}$. the former consistently held a substantial advantage. But at $28 \mathrm{~m} . \mathrm{p} . \mathrm{h}$. the drawbar pull of the two types was the same, and at 50 m.p.h., when the single was still exerting a pull of $1 \frac{3}{4}$ tons, the tractive power developed by the mineral engine was being used up entirely in its own propulsion. By an extension of the plotted curves, it appeared that the single engine would not be likely to reach the last-mentioned stage at a lower speed than approximatelv Ioo m.p.h. The broad principles already laid down as to the effect of driving wheel diameter and the coupling of axles on maximum speeds were further supported in the results of this test.

But when we attempt to apply these principles to observations of every-day running, in order to arrive at an accurate relation between design and performance, we are faced by contradictory results. The highest express locomotive speed ever recorded by the writer was one of exactly $90 \mathrm{~m}$. . h. by a six-coupled locomotive with a piston stroke of thirty inches. This was a two-cylinder 6ft. 8in. 4-6-o 
on the Great Western Railway, on an up Birmingham express, on the falling gradient from Beaconsfield to Denham, at no point exceeding $I$ in $r 75$ in steepness, with a load behind the tender of $3^{20}$ tons. At this speed, which was maintained for $I \frac{1}{4}$ miles, three alternate quarter miles being clocked with a chronograph in exactly so seconds each, the revolutions per minute totalled 378 and the mean piston speed was as high as $1,890 \mathrm{ft}$. per min. Two out of three ruling principles appear, therefore, to be falsified at the start, in that the Author's highest record of speed, in thirteen years of continuous train-timing covering nearly half a million miles, goes to an engine having three axles coupled and with the longest piston stroke of all locomotive types in this country. In addition to this the Author has timed speeds well in excess of 80 m.p.h. with at least five other six-coupled locomotive types-the $6 \mathrm{ft}$. 8in. fourcylinder 4-6-o engines of the Great Western Railway, the $6 \mathrm{ft}$. 7 in. London and South Western Railway four-cylinder 4-6-0's, the 6ft. 6in. Glasgow and South Western Railway

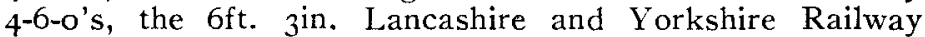
4-6-o's, and the 6ft. 3 in. London and North Western Railway " Experiments," which have given him definite records up to $86.5 \mathrm{~m} . \mathrm{p} . \mathrm{h}$. and a probable record of all but $90 \mathrm{~m} . \mathrm{p} . \mathrm{h}$. on another occasion, although the last-mentioned figure could not be guaranteed with accuracy, owing to smoke blowing down at a critical moment and obscuring the mile posts. At 86.5 m.p.h., however, the number of driving-wheel revolutions of an "Experiment" would be $3^{87}$ per minute, and the mean piston speed $\mathrm{r}, 677$ feet per minute. Clearly, therefore, the coupling of six wheels offers no hindrance to the attainment of very high speeds; and even the eight-coupled engine recently introduced by $\mathrm{Mr}$. Churchward on the Great Western Railway for mixed traffic service, with $5 \mathrm{ft}$. 8 in. wheels, has been timed at speeds in excess of 60 m.p.h.

When we come to the effect of driving wheel diameter on speed, we arrive at equally curious results. With a $5^{\mathrm{ft}}$. 8in. locomotive on the Great Western Railway, having four wheels coupled, the Author has recorded a maximum of 75 m.p.h., which involved a mean piston speed of I,606 feet per minute at $37 \mathrm{I}$ revolutions per minute. Several $5 \mathrm{ft}$. $8 \mathrm{in}$. and $5 \mathrm{ft}$. gin. engines have given records of over $70 \mathrm{~m} . \mathrm{p} . \mathrm{h}$. , and the various six-coupled four-cylinder Drummond engines of the London and South Western Railway, with only $6 \mathrm{ft}$. wheels, have on numbers of occasions been timed at speeds of $80 \mathrm{~m} . \mathrm{p} . \mathrm{h}$. and slightly over, on the heavy grades of the Salisbury and Exeter section. Seeing, 
therefore, that in defiance of theory, there appears in average every-day performance but little variation in maximum attainable speed as between single, four-coupled and sixcoupled engines, or engines with driving wheels of from $6 \mathrm{ft}$. to $7 \mathrm{ft}$. diameter or more, or engines with piston strokes of $24,26,28$, or as much as 30 inches, we are forced to look elsewhere for factors which control the results observed.

Undoubtedly one of the most important of these is the design of the exhaust ports and passages. The four-cylinder 4-0-0 engines of the Great Western Railway, which the Author has timed on a virtually level track at speeds from 75 to a little over 80 m.p.h., on several occasions, with loads up to 345 tons, have $14 \frac{1}{2}$-inch cylinders provided with ports 25 in. by 3 in., and the rapidity with which the steam can get away on the return stroke, with the consequent reduction in back pressure, must have a strong bearing on the extraordinary capacity of these engines for high speed. In this connection the Author is of opinion that part at least of the revolution in locomotive performance which has accompanied the introduction of superheating, and which by many is credited to superheating alone, must be attributed to the simultaneous general introduction of piston valves in place of slide valves, which allow the steam to escape more rapidly from the cylinders. All the highest speed records noted by the Author on level track have been made by piston valve engines, without exception, and the generas rise in maximum speeds in the present, as compared with the closing decades of the last century, is doubtless largely due to this cause. In regard to the proven fact that certain express locomotive types have shown themselves capable of higher speeds during recent years than at any time previously, Mr. E. L. Ahrons advances the interesting theory that the increasing hardness of steel rails and steel tyres, especially the former, has had the effect of lessening the resistance to motion occasioned by the undulatory motion of the rails between the supporting chairs as the rolling load passes over them. In explanation of the fact that single-driver locomotives show little or no higher capacity for speed than coupled engines, it must be remembered that single engines suffer from constant; : even if slight, slipping of the driving wheels when running at speed, so that the actual number of revolutions made by the driving wheels is greater than the theoretical number, in covering any given distance. The same consideration, in a more limited degree, doubtless applies to a comparison between the maximum speeds attained by four-coupled and sixcoupled engines respectively; that is to say, within limits 
an increase of adhesion weight tends to balance, in its effect on speed, the increased resistance offered by the coupling of three axles as compared with two.

But in any attempt at exact estimation of the relative influence of these controlling factors on speed, the investigator is hampered by the serious lack of data bearing on the subject. So far as railway companies themselves are concerned, drivers and guards compile " journals" of the running, with details of delays and their causes, but the only use to which these are usually put is that of allocating the responsibility for delays-whether caused by engineering cautions, "traffic" or "locomotive" -and, incidentally, this use furnishes a fruitful source of contention between the departments concerned. As bases of scientific investigation these journals are valueless, being compiled by interested parties, lacking in detail and with little regard for accuracy, as witness the famous example of the guard who booked one of the racing trains to Aberdeen of 1895 from Portobello into Edinburgh, three miles, in two minutes-an average of 90 miles per hour despite an intermediate rise of $I$ in 80 and the slowing down to a dead stop at Waverley! I mention this specially as being a historic trip on which accuracy of observation was more than usually needed. On such special occasions as the trials of engines of a new type, it is customary for the locomotive department of the railway company concerned to take considerably more detailed particulars of the running of the engine, including indicator diagrams, and, where a dynamometer car is available, continuous records of the drawbar pull, so that it is possible to compare with accuracy the horse-power developed and the running speeds observed. But these are necessarily more or less rare occasions, and it is a matter of common knowledge that the locomotives of a class rarely succeed in living up to the standard set by the pioneer engine in this way. Further, the results of such trials are only intermittently made public. Still more rare have been interchanges of engines between one company and another; here again it is only in the minority of instances that the valuable information afforded by such comparisons has been available to the' public, principally, one supposes, because the company whose locomotives have shown up worst in the trials has a rooted, if natural, objection to the fact becoming public property. Railway companies' records, therefore, do not afford much help in investigating the relation between locomotive design and performance.

For a number of years the Author has contributed to one of the monthly railway journals an article on this subject. 
Of this article he readily recognises the limitations. The nature of his experience tends to make such an article work back, by way of deduction, from performance to practice, rather than forward, by way of anticipation based on design, from practice to performance. At the same time the article deals with certain aspects only of a very complex subject. A monthly causerie of this character, in a popular journal, must of necessity defer to a certain extent to the side of the subject which makes the most popular appeal-the work of express locomotives on high speed trains, in which locomotive performance is seen in its most spectacular aspect. Again, to complete the survey of the subject, details are required of the management of the engine throughout the run, and the consumption of fuel, which are not available unless the observer makes every journey on the footplate. To make the survey absolutely comprehensive, details of the cost of maintenance should also be included-the accurate ascertainment of which in relation to work performed becomes increasingly difficult in these days of double and treble manning of engines-so that all the essential considerations bearing upon locomotive efficiency may be brought into consideration.

On a fuel or heat basis the locomotive is probably the most inefficient of all steam engines-it has an over-all thermal efficiency averaging well under ro per cent.-and on this account the Author would suggest the desirability of a more detailed study of actual locomotive performance than has hitherto taken place. A continuous and exhaustive inquiry into the running characteristics of different classes of locomotive, correlated in its details to the costs of construction, operating and maintenance, and taking into account the varying methods of drivers, should prove a mine of information to those engaged in locomotive design. The effects of variations in design could be gauged, if not with absolute accuracy, certainly with a great deal more accuracy than is possible at present, when a new locomotive design, making its appearance, is sometimes successful and sometimes, even if infrequently, so much the reverse that no subsequent alterations can cure its defects. Further, if any limited measure of locomotive standardisation were to take effect in the near future, as a result of grouping, figures of this character would be of considerable service in determining the combination of the very varied dimensional ratios now favoured by British locomotive engineers necessary to produce the standardised engine of the most efficient performance. Should this Paper, and the discussion which follows, have the effect of directing more attention than 
hitherto to this relation between locomotive design and performance, the Author will feel amply rewarded.

\section{DISCUSSION.}

The Chairman: The Author seems to have formed the opinion that locomotive engineers do not possess data obtained from actual tests to guide them upon matters of design. They have quite a lot of information on various subjects obtained from numerous tests, but of course this information is not always published. To obtain particulars of the performance of the working of engines in ordinary service, I know of one railway on which tests were made extending over a number of months, with engines running ordinary passenger trains. These tests were made with at least a dozen engines of the same class, and taking the performances day by day, the results obtained from one engine were found to compare closely with those of others in the same class. In making tests with locomotives from the point of view of comparison, there are numerous difficulties to contend with. Quite a number of variations have to be taken into consideration. For instance, there is wind and weather variation, class of coal and different weights of trains, but the data obtained from individual engines approximated to the average of the performances of the engine as a whole. As the Author points out, sometimes it is found that one engine of a class does not do so well as the sister engines, but there is generally some good reason to account for this.

The Author has spoken about having big ports. I had experience of an engine which was built with cylinders having ports and passages of large capacity, and the results obtained were not satisfactory. The capacity of the passages, especially the exhaust passages, was reduced, and the result of extended trials and alterations gave valuable information, and new cylinders were designed and fitted to other engines of the same class with highly satisfactory results, both in regard to running and economy of coal consumption. Within limits, the longer the ports the better, but ports too wide must be guarded against, and it is also highly important that the cross sectional area of both steam and exhaust passages should be uniform and as short as possible. It is not good practice to allow the exhaust steam to escape into a big cavity and then have to compress it again to force it through a constricted blast pipe orifice in order 
to obtain the blast pressure necessary to maintain the draught on the fire to keep a full head of steam in the boiler.

Another point not usually given the full consideration it requires, is that a locomotive boiler has to generate more steam than any other class of boiler of the same size, and the question of the design of the blast pipe is important in this connection. The blast pipe has not only to discharge the steam from the cylinders, but has to do so in such a way that it will create a draught on the fire to enable the boiler to produce the steam required from it. If the blast pipe is not right, the boiler will not function satisfactorily. The orifice must not be too small or too large, and its position in relation to the tubes in the smokebox tubeplate must be just right to obtain the best results.

The Author refers to locomotives with single driving wheels; such an engine, whatever else may be said about it, is one of the most free-running engines possible. If, however, one of the wheel tyres wears more than the other, trouble with slipping is experienced, and to get the best results it is essential that the diameter of both tyres should be kept the same. When this is done, and with trains they are able to start, the engines will give a satisfactory performance with an economical consumption of coal.

Talking of performances, so long as the results obtained from an engine can be plotted to lie about a certain curve within maximum and minimum limits, the engine will cope with the working of the traffic satisfactorily.

Another point touched upon is the speed at which the maximum power of an engine is obtained. I think it may be truly said that the maximum power of a locomotive is developed at a certain piston speed, and it is necessary to proportion the wheels to suit the speed at which a locomotive needs to develop its maximum power. For working mineral trains, heavy loads at moderate speeds, an engine with small wheels is required, but for passenger trains, which run at higher speeds, it is necessary to have larger wheels.

Mr. W. Rowland (G.C. Rly., Gorton) : In the early part of the Paper the Author, in commenting on the assumed impossibility of designing a locomotive by other means, says "We therefore have recourse to ratios," and proceeds to set forth various ratios, such as tractive effort to heating surface, heating surface to grate area, and so on, which he quite gratuitously assumes are actually employed by the designer.

Although these ratios are apparently of great interest to the readers of popular literature on the subject, they hap- 
pen, with perhaps one exception, to be those with which any designer who knows his business is totally unconcerned.

In fact, the Author, perhaps not intentionally, accuses the designer of total ignorance of the principles of his business and reduces him to slavish copying of proportions which have been found more or less satisfactory as the result of a course of errors or happy accidents in the past. Let me assure him that the state of the art is hardly as bad as that, whatever it may have been once. Certainly ratios do enter into design, but they are not those quoted by the Author.

For example, the ratio of firebox surface to volume, which is really a measure of the water-cooling effect of the fircbox sides, has a very important bearing on the completeness of combustion possible at high rate of firing, particularly when bituminous coal or oil is used as fuel. The ratio of firebox volume to fuel consumed per unit of time is also important. Then again, the ratio of hydraulic mean depth of a tube, or set of tubes, to its length is of importance as a measure of the heat-absorbing capacity of the tube or set. The ratio of the total resistance to gas flow of a set of tubes, which is deduced from the last quoted ratio, hydraulic mean depth to length, in conjunction with the number, is a measure of the power required from the blast, and is therefore of service in conjunction with other considerations in designing a boiler to give the required power and efficiency. For high speed work, in particular, the ratio of mean port opening, on both steam and exhaust edges, to cylinder volume is likewise important; so is the ratio of the internal surface of cylinder ports and piston head to their volume, as this ratio is largely concerned in determining the cylinder losses, and therefore the engine, as distinct from the boiler, efficiency of the locomotive.

The ratio of tractive effort to adhesive weight is about the only one of the Author's ratios that is of real importance, but even this ratio is by no means a constant for all engines, since it is by no means necessary to base it on the normal or full gear tractive effort for all classes of locomotive. In fact, a single driving wheel engine, designed with a nominal tractive effort to adhesion ratio suitable for a slow-running mineral engine, would be badly under-cylindered and most uneconomical at the express speeds for which such engines were designed, and to some extent the same holds good for four wheels and even six wheels coupled engines. May 1 assure the Author that modern locomotive design had progressed far beyond the rule-of-thumb methods which one would infer from his remarks to be still in vogue. The 
Author, further on, refers to the four-cylinder Great Western engines having a lap of $\mathrm{I} \frac{5}{8}$ in. Perhaps he can also tell us the full gear valve travel which must be very much greater than is usual in British practice to prevent these engines constantly refusing to start. Is it a fact that these engines have a full gear valve travel of 7 in. or so? If not, they must have a starting notch in the steam lap as is sometimes done in American engines designed to give an early cut-off in full gear. I have not so far heard of this expedient having been adopted in this country.

It would have been of far greater interest to members of the Institution had the Author given records of longsustained high speed up-grade work with heavy loads, as this is the true measure of locomotive efficiency.

Mr. E. W. Selby (L. \& N.W. Rly., Horwich): The Author refers to the ordinary every-day performance of a locomotive as opposed to special test runs. I think he is quite right, as there is extremely little published information about this subject. Some railways have test runs with a dynamometer car, but as a rule the engine is specially tuned up and picked coal is used. The results obtained are doubtless valuable for comparison with other similar test runs, but they do not give much idea of what those locomotives as a class may be expected to do day in, day out, in all weathers, throughout the year.

As regards tractive effort, the two chief factors limiting the power of a locomotive are :-

I. Adhesion (when starting and running slowly).

2. Steam producing capacity of boiler (when running fast).

As the tractive effort formula does not take either of these factors into account, it seems rather futile and is often misleading.

Some reference has already been made to Great Western locomotives. These engines have quite exceptionally large steam and exhaust ports, and this point, coupled with their high boiler pressure, and. with the fact that they have more lap on their valves than most locomotives, is largely responsible for the extraordinary turn of speed which these engines undoubtedly possess. The long lap enables the engines to be notched up to a very considerable degree without undue compression, thus, whilst cutting off early, the exhaust port remains open until quite late in the stroke.

Mr. J. H. Haigh (L. \& N.W. Rly., Horwich) : No formula can possibly take into consideration the many variable 
factors, such as quality of coal, permanent way, wind and weather, and it appears that the only comparison of any value is that of many actual test runs made under as nearly as possible identical conditions.

It is a well-known fact that engines built to the same drawings behave in very different ways, probably owing to undetected variations in their structure, as mentioned by the Author; and it hardly seems just to pit one engine of a class against one engine of a different class under anything but constant conditions, and draw conclusions or modify formula on the data thus obtained. Much valuable data can be gathered from a single trial run with a dynamometer car, but the usefulness of an engine, or type of engine, can only be decided on the records of many engines over a considerable period, provided always that the operating department is not given a free hand with loading or that only maximum speed is required.

Mr. E. N. R. Hart (L. \& N.W. Rly., Horwich): Although the Author has said a good deal about tractive effort, I do not think that it is of very great value to the department who use the engines. The traffic department is merely concerned in the hauling capacity of the engine, and the tractive effort is not of very much value in rating this; and the question of adhesion enters largely into the matter in fixing the load which the engine shall be booked to take.

The Author makes comparisons between the Great Northern "Atlantic" type and the Lancashire and Yorkshire 2-4-2 superheated tank. Although the former may on occasions be called upon to work mineral trains, I think this will chiefly be found to be due to the balancing of the engines in the course of a day's work, and I do not think the engines are regularly used for working mineral traffic. Also, the work for which these engines were designed does not make them comparable to the Lancashire and Yorkshire engines; the conditions of the line and the work are so very different; the gradients on which the superheater tanks work are, on the average, more severe than those on the Great Northern line.

As regards the Author's remarks on the question of the dynamometer car tests, I think that these are very useful, and if it were not for the expense, it would be advantageous to have a good many more of them. But it is necessary that care should be taken in conclusions drawn from the results, as the conditions which engines work on during these tests differ very much from the regular work of the engine. 
Mr. J. Parry (G.C. Rly., Gorton) : The Author expressed the opinion that piston valves allowed a freer escape for exhaust steam than did slide valves. This is not necessarily so. With piston valves the steam leaving the cylinder has to break up into a number of streams in order to pass to the inside of the liner, where these streams converge and then suddenly have their direction changed through an angle of 90 degrees. Sudden changes of direction and velocity are as bad as throttling. Probably a balanced slide valve with the exhaust passage through the back offers the least resistance.

I do not think that the quoted opinion that harder rails and tyres reduced the undulatory motion of the road can be maintained. The coefficient of elasticity, Young's modulus, of the harder steel is very little different to that of the softer, and therefore the rails, unless at the same time deeper, will not be stiffer. The rolling friction of hard materials is less than with soft; but, within the range of hardness permissible in railway practice, the difference is too small to be considered. The object of using harder steel is, of course, durability.

The Author complains that railway companies do not publish reports of locomotive performances when apparently unfavourable. It would be very imprudent of them to do so, for these results getting into the hands of non-technical perople might easily be the cause of much mischief.

One of the comparisons of engines made in the Paper is between Mr. P. Stirling's 8ft. single driver and Mr. Ivatt's "Atlantic," as regards their relative heating surface. In Mr. Stirling's time coal was comparatively cheap, therefore fuel economy was not so much in the forefront as in later times. To get an engine low in first cost and maintenance, simple and reliable, it is quite permissible to sacrifice something in the way of fuel economy. Later, as in Mr. Ivatt's time, large heating surfaces were in vogue, this being then considered the way to fuel economy. History ofter explains things.

The Paper will serve at least one useful purpose, that of emphasising the fact that the design of locomotives, like the design of most other things, requires a knowledge of many matters other than the arithmetical rule of simple proportion.

Mr. E. M. Gass (L. \& N.W. Rly., Horwich) : Mr. Allen is to be complimented in bringing a Paper of this character before us, as it provides food for thought regarding some: 
of the unsolved problems connected with the steam locomotive.

The Author makes no comments in respect to the loads hauled by the "Stirling" singles and the "Ivatt" "Atlantics." There is little doubt that the running performances of the former have hardly ever been surpassed when hauling loads equal to their capacity, but the constantly increasing demands of the running department for heavier trains taxed these engines beyond their limit, the result being that a more powerful machine became necessary.

I believe the success of the Great Northern singles was due, in a large measure, to the low ratio grate surface to heating surface, being $I$ to $5^{8}$ as compared with $I$ to 80 in the case of the "Atlantics." This low ratio results in a higher evaporation value; for instance, at a speed of 30 miles per hour the evaporation values are $8.3 \mathrm{lbs}$. and 6.25 lbs. respectively per pound of coal with a feed water temperature of $100^{\circ} \mathrm{F}$.

I have endeavoured to figure out the loads that the two designs are capable of hauling on the assumption that they are running at a speed of 30 miles per hour on an up-grade of $\mathrm{I}$ in 200 , this being about the ruling grade over the section of the line of the Great Northern Railway, Leeds to King's Cross and vice versa. The detailed statements A, B, C show how the figures are arrived at. The loads behind the drawbar in the case of the single driver is 283 tons as compared with $39+$ tons for the "Atlantic."

I have also estimated the rate of coal consumption. Assuming a speed of 70 miles per hour with a steam cut-off of I 5 per cent., and cylinder clearance of 8 per cent., the "Stirling" engine, on this assumption, would be burning coal at the rate of $157 \mathrm{lbs}$. per square foot of grate surface per hour, whereas Ivatt's "Atlantics" would be consuming at the rate of I $5 \mathrm{lbs}$. The rate of the former is considerably above economical limit, which is about I3olbs. See Table D.

With respect to high speed, I should like to mention a record of 94 miles per hour attained by one of Sir John A. F. Aspinall's "Atlantics" when hauling a train of four bogie coaches, practically roo tons behind drawbar, between Rainford Junction and Kirby, on the Manchester and Liverpool line. This section of the road is on falling grades, the ruling being $I$ in 235. The time occupied in passing the two points was $3 \frac{1}{4}$ minutes, the distance being five miles I79 yards. This engine was fitted with Geo. Hughes' patent compression ball release balanced slide valves at the time.

The bad starting qualities of the single driver are well known. In the case of the Great Northern engine the 
weight available for adhesion was 18 tons, and only 25 per cent. of this weight could be utilised, or 10,080 lbs. tractive force.

This figure gives a mean effective pressure in the cylinders of Io8lbs. or $6 \mathbf{I} .7$ per cent. of the boiler pressure. The corresponding piston speed at this pressure is 310 ft. per minute, ${ }^{*}$ which in the case of the Great Northern single is equal to a running speed of nearly 20 miles per hour.

This engine has therefore to attain this speed before the tractive effort is absorbed by adhesion.

$$
\text { M.E.P. }=\frac{10080 \times 97.5}{18 \times 18 \times 28}=1081 \mathrm{bs} .
$$

Per cent. of boiler pressure $=61.7$.

\section{COMPARISON OF LOADS HAULED BEHIND DRAW. BAR AT 30 MILES PER HOUR ON A RISING GRADE OF 1 IN 200.}

\section{A. STIRLING'S 8ft. SINGLES.}

Running speed, 30 miles per hour or $2,640 \mathrm{ft}$. per minute.

Piston speed, $483 \mathrm{ft}$. per minute.

Coal burnt per sq. ft. of grate surface per hour at a piston speed of $4_{3} \mathrm{ft}$. per minute $=961 \mathrm{bs}$. ( $($ see Fig 8 , Vol. IX., Paper No. 73.)

Total heating surface, sq. $\mathrm{ft} .=\mathrm{I}, \mathrm{O} 3^{2}$.

Grate surface, sq. ft. $=\mathbf{I 7 . 7 5}$.

Ratio of grate to heating surface $=\frac{1,03^{2}}{17 \cdot 75}=\mathrm{I}$ to $5^{8}$.

$$
17 \cdot 75
$$

Coal burnt per sq. ft. of heating surface per hour $=\frac{9^{6}}{5^{8}}=\mathbf{r} .66$.

Lbs. of steam evaporated at a piston speed of $483 \mathrm{ft}$. per minute $=8.3$ (see Fig. 9, Vol. IX., Paper No. 73).

Total coal burnt per hour $=96 \times 17.75=1,705$ lbs.

Total evaporation per hour $=\mathrm{I}, 705 \times 8.3=14,15 \mathrm{I}$ lbs.

Steam consumption per i.h.p. hour at a piston speed of $483^{\mathrm{ft}}$. per minute $=25.3^{\mathrm{lbs}}$. (see Fig. Io, Vol. IX., Paper No. 73).

Indicated horse-power hour $=\frac{{ }^{\mathrm{I}} 4, \mathrm{I}_{5} \mathrm{I}}{25 \cdot 3}=559$.

* See Fig. 1, "The Relation of Cylinder and Boile- Power to Locomotive Rating," by E. M. Gass, Vol. IX., Paper No. 73. 
Corresponding tractive power $=\frac{559 \times 33,000}{2,640}=6,990$.

Total weight of engine and tender $=85$ tons.

Resistance of engine and tender at 15 lbs, per ton $=85 \times 15$ $=1,275$ lbs. (Cole's Locomotive Rating).

Effective drawbar pull $=6,990-1,275=5,715$ lbs.

Resistance due to grade $=\frac{2,240}{200}=$ r. $1.2 \mathrm{lbs}$, per ton.

Resistance of 25-ton passenger cars (Lawford H. Fry) $=9$. olbs. per ton.

Total resistance $=$ I I $.2+9 \cdot 0=20.2 \mathrm{lbs}$. per ton.

Tons hauled behind drawbar $=\frac{5,715}{20.2}=282.9$.

\section{B. IVATT'S "ATLANTICS."}

Piston speed, $508 \mathrm{ft}$. per minute.

Coal burnt per sq. ft. of grate surface per hour at a piston speed of $508 \mathrm{ft} .=$ roolbs. (see Fig. 8, Vol. IX., Paper No. 73 ).

Total heating surface, sq. ft. $=2,500$.

Grate surface, sq. $\mathrm{ft} .=3$ o.9.

Ratio of grate to heating surface $=\frac{2,500}{30.9}=\mathrm{I}$ to 80 .

Coal burnt per sq. ft. of heating surface per hour $=\frac{100}{80}$ $=\mathrm{I} .25 \mathrm{lbs}$.

Lbs. of steam evaporated at a piston speed of $508 \mathrm{ft}$. per minute $=6.25$ (see Fig. 9, Vol. IX., Paper No. 73).

Total coa! burnt per hour $=100 \times 30.9=3$,ogolbs.

Total evaporation per hour $=3,090 \times 6.25=19,31$ albs.

Steam consumption per i. h.p. hour at a piston speed of 508ft. per minute $=25.25 \mathrm{lbs}$. (see Fig. Io, Vol. IX., Paper No. 73).

Indicated horse-power hour $=\frac{19,312}{25.25}=764$.

Corresponding tractive effort $=\frac{764 \times 33,000}{2,640}=9,55$ olbs. 
Total weight of engine and tender $=$ ro6. 4 tons.

Resistance of engine and tender at I 5 lbs. per ton (Cole's

Locomotive Rating) $=106.4 \times$ I $_{5}=\mathrm{I}, 5961 \mathrm{bs}$.

Effective drawbar pull $=9,55^{\circ}-\mathbf{r}, 596=7,954^{\mathrm{lbs}}$.

Resistance due to grade $=\frac{2,240}{200}=$ I r.2lbs. per ton.

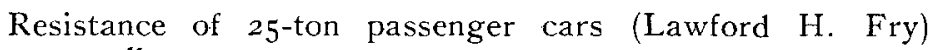
$=$ glbs. per ton.

Total resistance $=I 1.2+9.0=20.21 \mathrm{bs}$. per ton.

Tons hauled behind drawbar $=\frac{7,954}{20.2}=393.8$.

\section{COMPARISON OF LOADS HAULED AT 30 MILES PER HOUR ON AN UP GRADE OF 1 IN 100.}

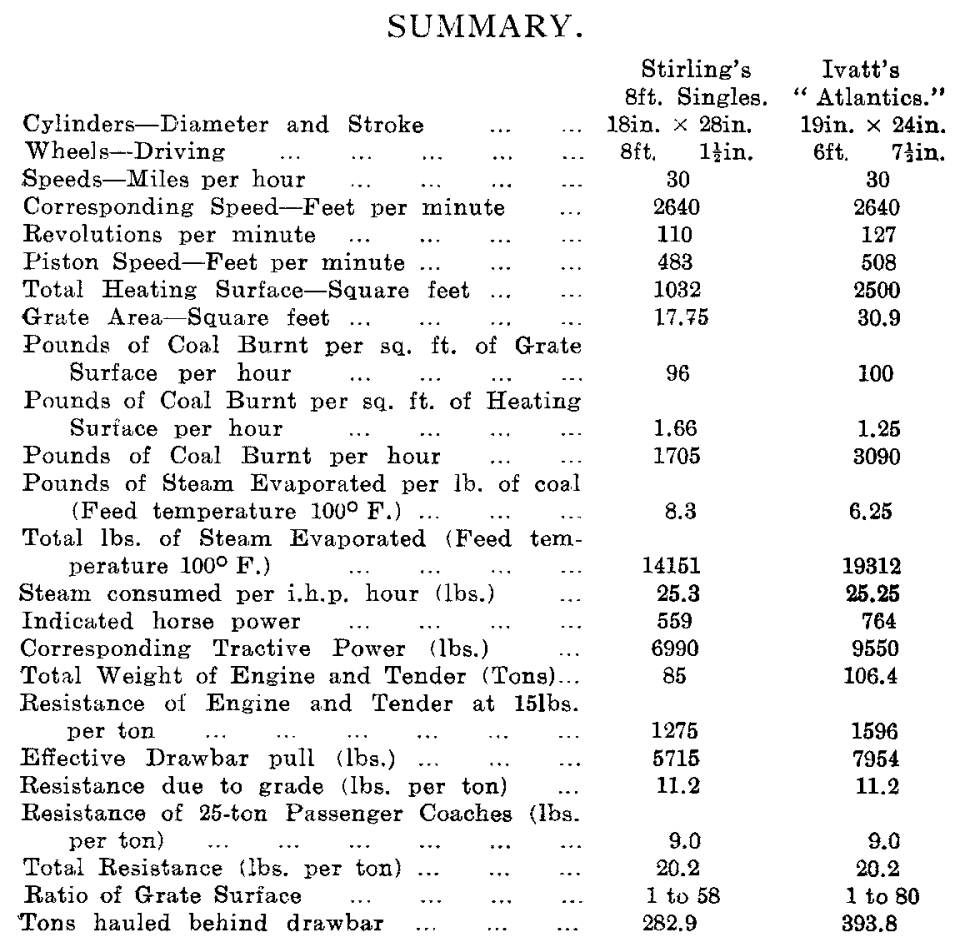




\section{COAL CONSUMPTION.}

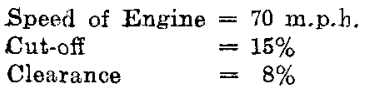

\begin{tabular}{|c|c|c|c|c|}
\hline $\begin{array}{lll}\text { Wheel diameter } & \ldots & \ldots \\
\text { Cylinder diameter } & \ldots & \ldots \\
\text { Cylinder stroke } & \ldots & \ldots\end{array}$ & $\begin{array}{l}\cdots \\
\cdots \\
\cdots\end{array}$ & $\begin{array}{l}\cdots \\
\cdots \\
\cdots\end{array}$ & $\begin{array}{l}\text { 8ft, } 1 \frac{1}{2} \mathrm{in} \\
\quad 18 \mathrm{in} . \\
28 \mathrm{in} .\end{array}$ & $\begin{array}{l}\text { 6ft. } 7 \frac{1}{2} \text { in. } \\
\text { 19in. } \\
24 \text { in. }\end{array}$ \\
\hline $\begin{array}{l}\text { Volume of steam per stroke } \\
\text { Volume of cylinder } \\
\text { Cu. ft. of steam per stroke } \\
\text { Rezs. per hour of drivers } \\
\text { Strokes per hour ... } \\
\text { Steam used per hour per eyli } \\
\text { Steam used per hour per engin } \\
\text { Boiler pressure (absolute) } \\
\text { Weight of } 1 \text { cu. ft. of steam } \\
\text { Pounds of steam used per b } \\
\text { Assumed evaporation of } 8 \text { lbs. } \\
\text { lb. of coal } \\
\text { Grate area ... } \quad \ldots \\
\text { Coal burnt per sq. ft. grate }\end{array}$ & $\begin{array}{c}\ldots \\
\ldots \\
\ldots \\
\ldots \\
\ldots \\
\text { inder } \\
\text { e } \\
\ldots \\
\text { our } \\
\text { of wa } \\
\ldots \\
\ldots\end{array}$ & $\begin{array}{lr}\ldots & . . \\
\ldots & . . \\
\ldots & . . \\
\ldots & . . \\
\ldots & . \\
& \\
\ldots & \\
\text { ylinders } \\
\ldots\end{array}$ & $\begin{array}{c}(8+15 \%)=23 \% \\
4.11 \mathrm{cu} . \mathrm{ft} . \\
.945 \mathrm{cu} . \mathrm{ft} . \\
15,800 \\
31,600 \\
31,600 \times .945 \\
29,862 \mathrm{cu} . \mathrm{ft} . \\
59,724 \mathrm{cu} . \mathrm{ft} . \\
155 \\
.37237 \\
22,250 \mathrm{lbs} . \\
\frac{22,250}{8}=2,780 \\
17.75 \\
\frac{2,780}{17.75}=156.9 \mathrm{lbs} .\end{array}$ & $\begin{array}{c}23 \% \\
3.94 \mathrm{cu} . \text { It. } \\
.906 \mathrm{cu} \text {. ft. } \\
17,750 \\
35,50 \mathrm{c} \\
35,500 \times .906 \\
32,150 \mathrm{cu} . \mathrm{ft} . \\
64,300 \mathrm{cu} . \mathrm{ft} . \\
190 \\
.4445 \\
\frac{28,5501 \mathrm{bs} .}{28,550} \\
\frac{8}{30.9}=3,570 \\
\frac{3,590}{30.9}=115.5 \mathrm{lbs} .\end{array}$ \\
\hline
\end{tabular}

The Author: In reference to certain criticisms of the Paper I wish to emphasise that, so far from the slightest intention of " accusing the designer of total ignorance of the principles of his business," or of suggesting that "locomotive engineers do not possess data obtained from actual tests to guide them upon matters of design," I had no other idea in my mind at the time of writing the Paper than to draw attention to the lack of published information or data bearing on the subject dealt with. I do not doubt for a moment that many railway companies possess a considerable amount of statistical record in regard to the performances of their own locomotives, but as such records are seldom, if ever, made public, the locomotive world at large has no opportunity of benefiting by the knowledge thus acquired. It was in this connection that I stressed the fact that little has been published in regard to the direct trials which have taken place from time to time between the engines of different railways over the same road, which mist afford valuable comparative data. I am glad to have the agreement of several speakers as to the desirability of considerably extended dynamometer car and other tests, based $\epsilon$ specially on normal every-day work of locomotive performance; this was a matter raised also by $\mathrm{Mr}$. Whitelegg in 
his Presidential Address of the present year to the Glasgow Centre of the Institution. Although only three British railways possess dynamometer cars of their own, it is of interest to note that, when the forthcoming grouping is complete, three out of the four large groups will each control a dynamometer car of modern, or fairly modern, design, and the way will thus $b c$ opened for some exceedingly interesting comparisons between the performances of the many different types of engine working over each group of lines, and the eftects of the various special features of design that they incorporate. It is to be hoped that the results of all such comparisons will be made public, as they should add materially to the existing knowledge of the locomotive and its work. That the methodical German realises the value of such investigations is evident by the monumental treatise which has recently appeared on this very subject, dealing with the design and work, based on exhaustive trials, of all the leading classes of engine in Germany.

Mr. Rowland takes considerable exception to my remarks concerning ratios. In reply, I would point out that I have made no attempt to detail at length a wearisome series of all the numerous ratios employed, or which might be employed, in locomotive designing - this is merely incidental to the subject matter of the Paper-but, having quoted one or two, which may quite possibly be growing out-of-cate in these enlightened days, I added " and so on," to indicate the remainder, in regard to the relative importance of which I would not presume to disagree with Mr. Rowland. At the same time, as Mr. Rowland stresses a number of ratios relating in particular to the firebox, it would be interesting to know why practically all the modern engines of the Great Central Railway, with which $\mathrm{Mr}$. Rowland is connected-4-4-0 and 4-6-o express passenger, 4-6-o mixed uraffic and 4-6-o express goods, and both smallboilered and large-boilered 2-8-o mineral engines-have a firegrate area of precisely $26 \mathrm{sq}$. $\mathrm{ft}$., irrespective of the work that they are called upon to perform. This seems rather to conflict with Mr. Rowland's previous remarks as to "the slavish copying of proportions, which have been found more or less satisfactory as the result of a course of errors or happy accidents in the past "; it is probably one of the unfortunate results which beset the seeker after standardisation.

In his choice of types of engine to compare on a ratio basis, I was perhaps ill-advised, as pointed out by Mr. Hurt and others, in selecting extreme cases, rather than instances. of engines performing, as nearly as possible, the same 
duties; leaving such comparisons out of account, however, nothing has been said in the discussion to contradict the assertion that different locomotive engineers not infrequently proceed on materially varying principles of design, even when designing engines to perform work of practically uniform quality, and that that difference is apparent in the variations in ratio adopted by one designer as compared with another.

I am unable to agree altogether with Mr. Parry in regard to the comparative freedom with which exhdust steam escapes through piston valves and slide valves, even though, with the former, the direction of the steam may be changed through an angle of godeg. The slide valve (except in the somewhat rare case of valves exhausting through the back) compels a momentary reversal of I8odeg. under the back of the valve, generally followed, in cases where the valves are above or below the cylinders, by a further immediate reversal through godeg. The relative hindrance offered by these two changes of direction would seem greater than that occasioned by the one change of direction and the thickness of the port bars in the piston valve, and may in some measure account for the differences in performance instanced in the Paper.

Mr. Parry's remarks in regard to the increased hardness of rails and tyres are very interesting. So far as rails are concerned, in addition to increased hardness, represented in the case of the Great Eastern Railway by an average increase in ultimate tensile strength from about 44 to 53 or 54 tons per sq. in. during the last few years alone-rails have increased in depth by $\frac{1}{1}$ to $\frac{1}{2} \mathrm{in}$. during two or three decades past, as well as in the thickness of head, web and foot, so that they form altogether stiffer beams than previously in their unsupported lengths. 